Supporting information

\title{
Programmable Color in a Free-standing Photonic Microgel Film with Ultra-fast Response
}

Zhujun Zeng, Jinhui Liang, Ronghua Yu, Jiahui Liu, Meiwen Cao, Shengjie Wang*, Yongqing Xia*

Center for Bioengineering and Biotechnology, College of Chemical Engineering

China University of Petroleum (East China), Qingdao 266580, China.

Correspondence and requests for materials should be addressed to YX: xiayq@upc.edu.cn 


\section{Supporting Table}

Table S1. polymerization conditions of the pNIPAAmStAA microgel with different hydrodiameter.

\begin{tabular}{lllllllll}
\hline Microgel & NIPAAm/g & St/g & MBA/mg & AA/mg & Initiator $/ \mathrm{mg}$ & $\mathrm{H}_{2} \mathrm{O} / \mathrm{mL}$ & Temperature $/{ }^{\circ} \mathrm{C}$ & $\begin{array}{l}\text { Stir } \\
\text { speed }\end{array}$ \\
\hline A & 1.5 & 0.5 & 41 & 69 & 60 & 100 & 70 & 250 \\
B & 1.5 & 0.5 & 21 & 69 & 60 & 100 & 70 & 250 \\
$\mathrm{C}$ & 3.0 & 1.0 & 41 & 138 & 120 & 100 & 70 & 250 \\
$\mathrm{D}$ & 3.0 & 1.0 & 41 & 138 & 120 & 100 & 90 & 350 \\
\hline
\end{tabular}

\section{Supporting Figures}

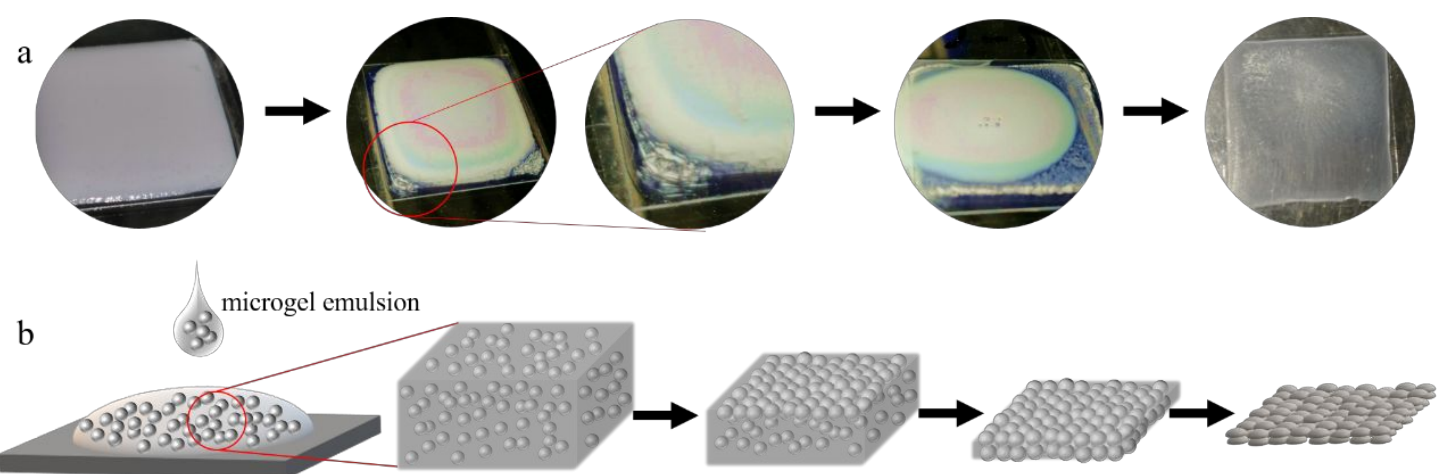

Figure S1. (a) Representative surface color of the microgel emulsion coated on glass substrate during the drying process; (b) schematic illustration of the self-assembly process of the microgels in the drying stage. 

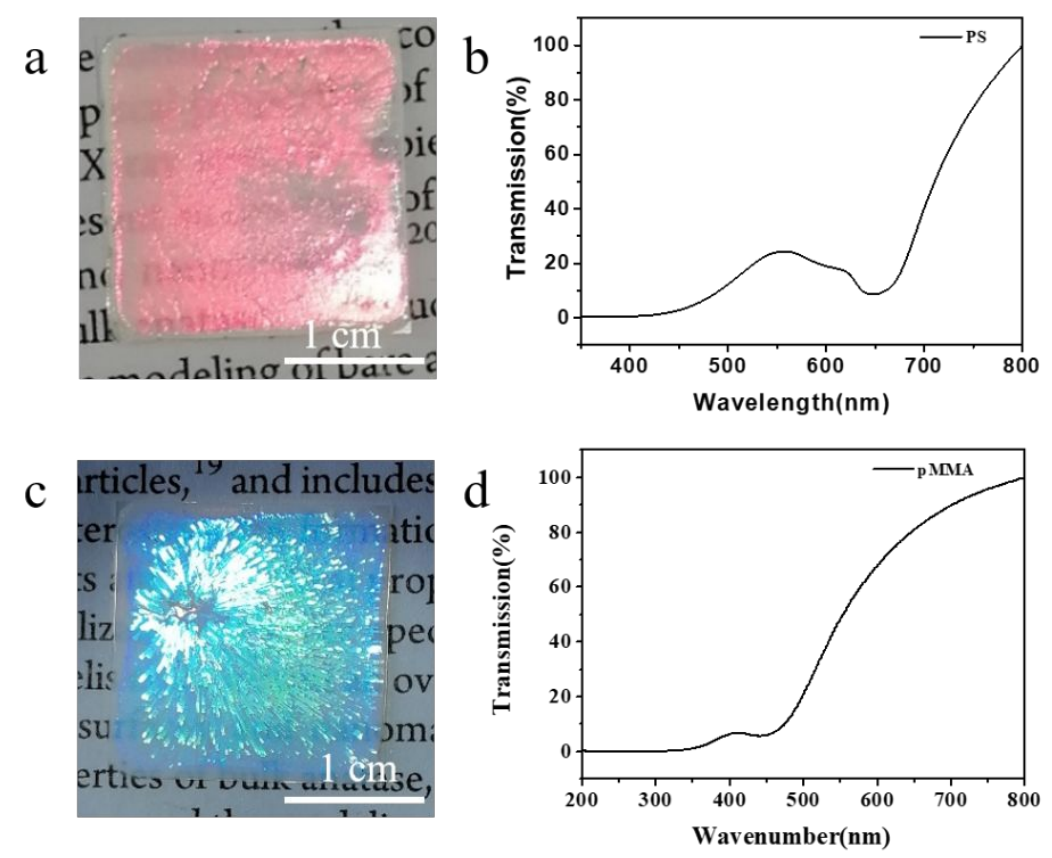

Figure S2. (a) Optical photograph of the film composed of PS spheres with diameter of $265 \mathrm{~nm}$; (b) the transmittance spectrum of the PS film; (c) Optical photograph of the film composed of pMMA spheres with diameter of $241 \mathrm{~nm}$; (d) the transmittance spectrum of the pMMA film.

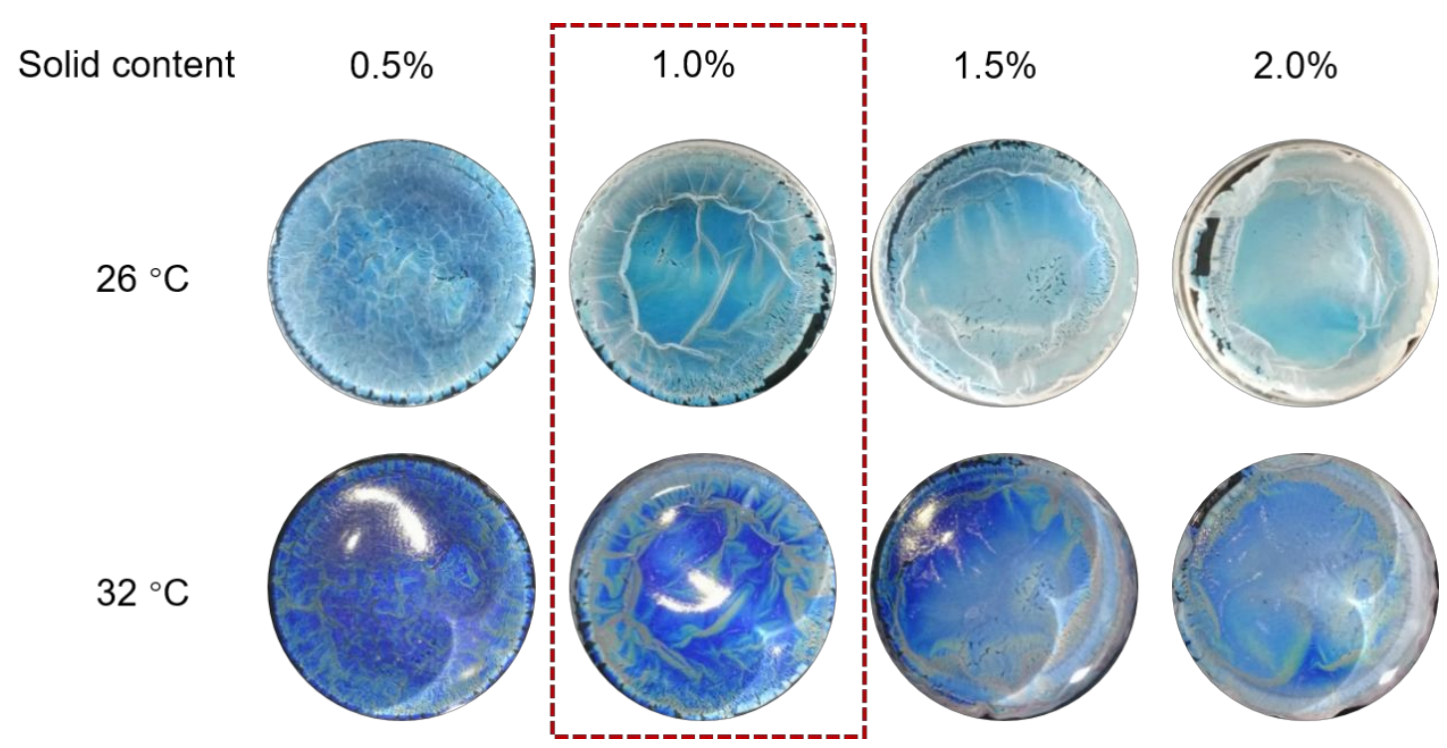

Figure S3. The effect of solid content of the microgel emulsion on the color of the film. 

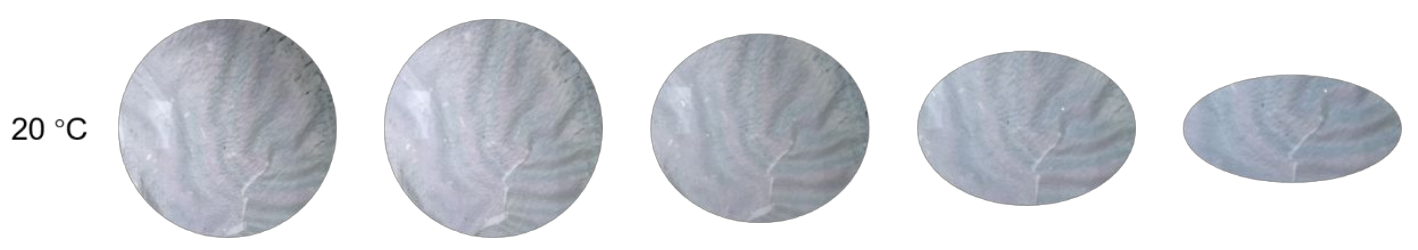

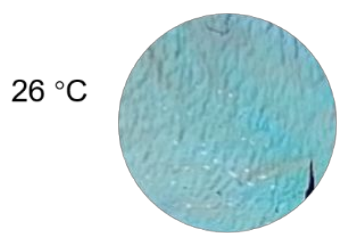

$0^{\circ}$

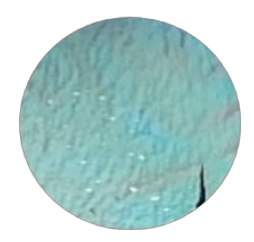

$15^{\circ}$

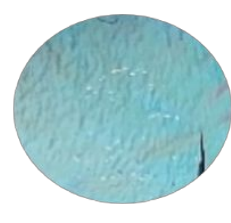

$30^{\circ}$

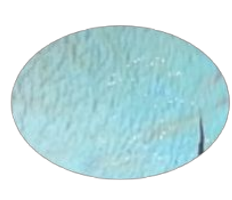

$45^{\circ}$

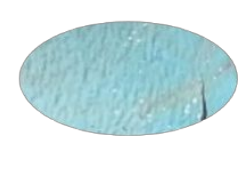

$60^{\circ}$

Figure S4. (a) photographs of microgel film viewed from different viewing angles under ambient light; the microgel film at the temperature of $20^{\circ} \mathrm{C}$ and $26^{\circ} \mathrm{C}$.

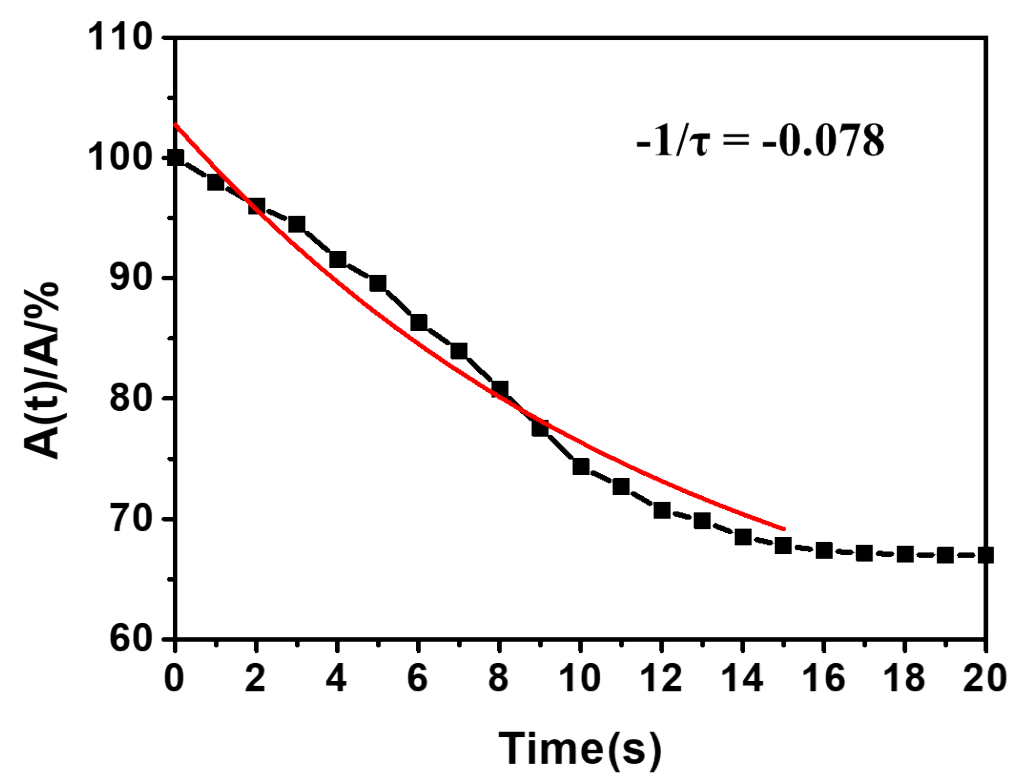

Figure S5. The temperature-responsive kinetics of the bulk hydrogel from $20{ }^{\circ} \mathrm{C}$ to $40{ }^{\circ} \mathrm{C}$. Respective data were fitted by the single decay function with $\mathrm{R}^{2}=0.975$. 

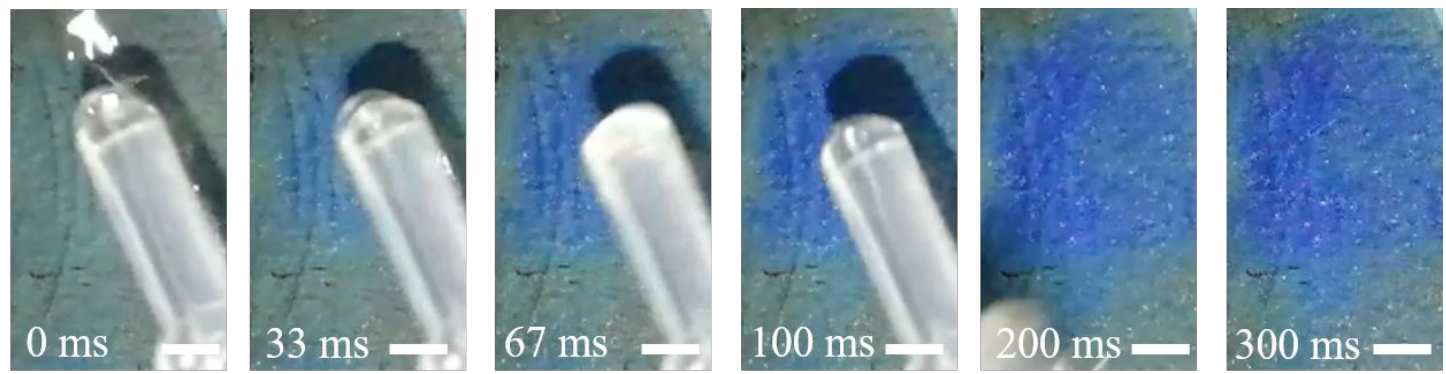

Figure S6. The time lapse of the microgel film (room temperature) when a drop of hot water (about $40^{\circ} \mathrm{C}$ ) was dropped on the surface, its color turned to blue immediately, less than $33 \mathrm{~ms}$. Scale bars are $0.2 \mathrm{~cm}$.

a

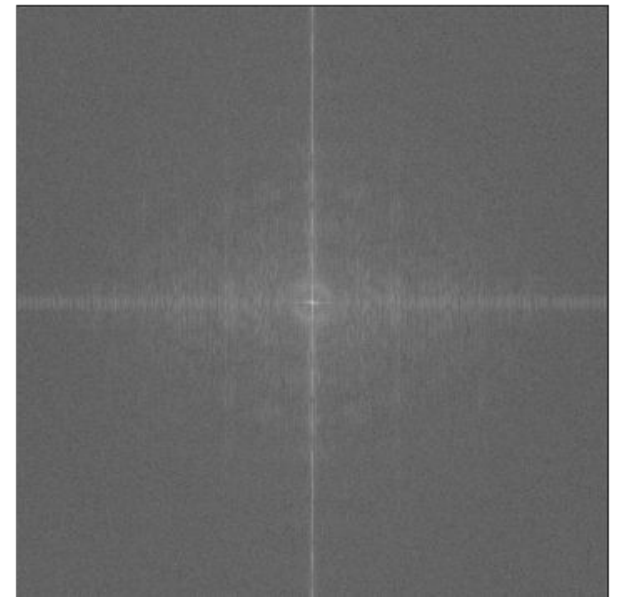

b

Figure S7. FFT images (derived from SEM image of Figure 4e, f) of microgel film at $20^{\circ} \mathrm{C}(\mathrm{a})$ and $35^{\circ} \mathrm{C}(\mathrm{b})$. 

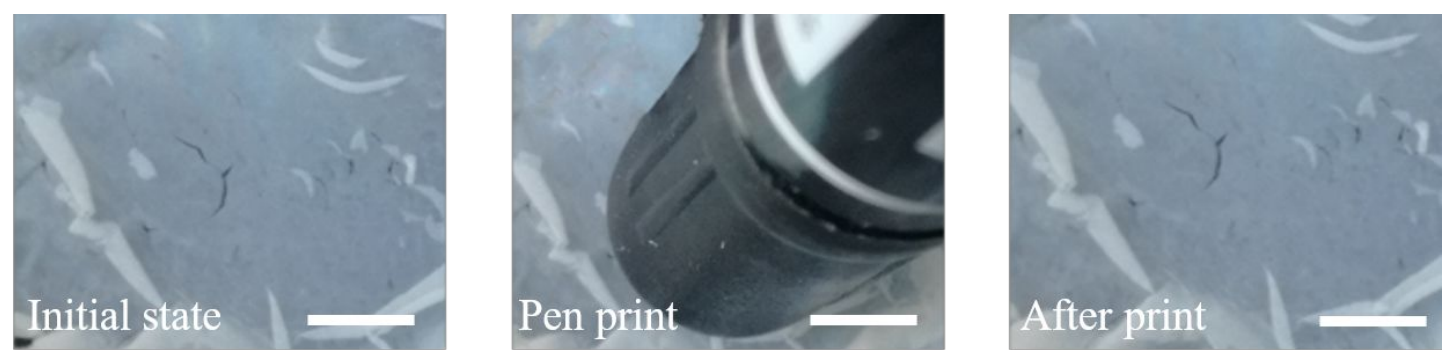

Figure S8. The microgel film displayed no color change when a pen cap was pushed on it. (a) The initial state of the microgel film; (b) a pen cap was pressed onto the microgel film; (c) no color appeared after the pen cap removed immediately. Scale bars are 0.4 $\mathrm{cm}$.

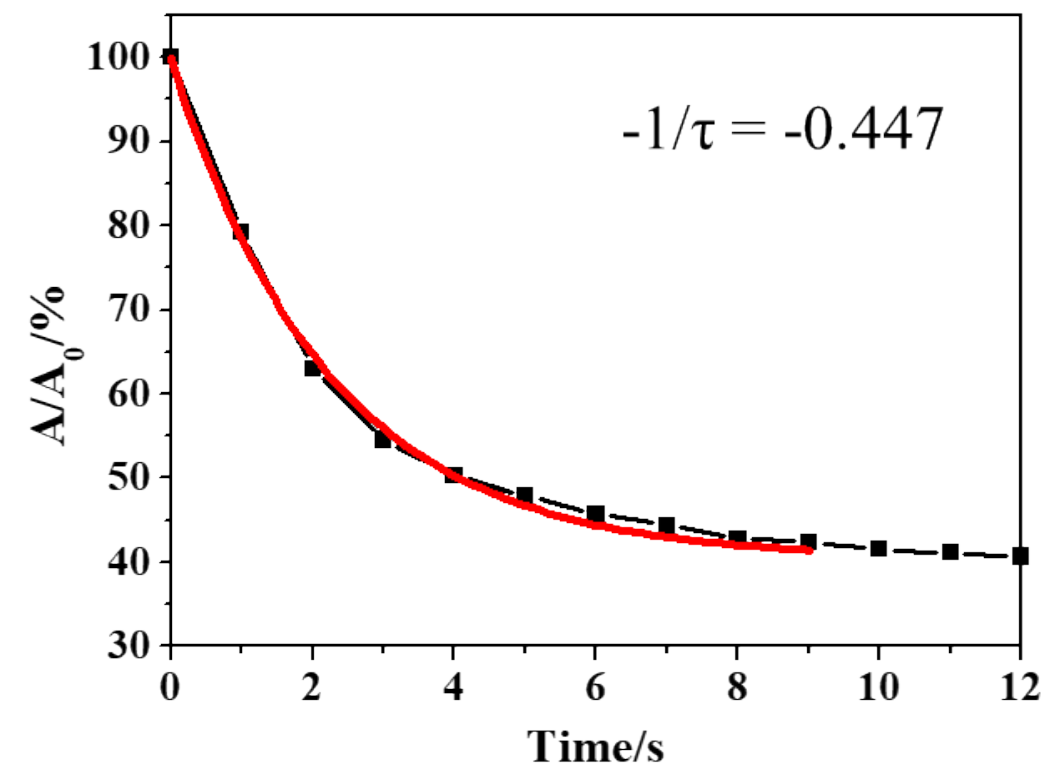

Figure S9. The pH-responsive kinetics of the microgel film from $\mathrm{pH} 8.3$ to $\mathrm{pH} 2.0$. During $\mathrm{pH}$ change, the temperature was maintained at $20^{\circ} \mathrm{C}$. Respective data were 
fitted by the single decay function with $\mathrm{R}^{2}=0.996$.

\section{Supporting Movies}

Movie S1: The dynamical color change when the microgel film was put into $40{ }^{\circ} \mathrm{C}$ water from $20^{\circ} \mathrm{C}$.

Movie S2: The dynamical color shifting process when $0.1 \mathrm{M} \mathrm{HCl}$ was adding from one side of the microgel film. 